\title{
Neurocognitive effects of phobia-related stimuli in animal-fearful individuals
}

\author{
BRUNO KOPP \\ Municipal Hospital and Technical University, Braunschweig, Germany \\ and \\ RENÉ ALTMANN \\ Humboldt University, Berlin, Germany
}

\begin{abstract}
Two experiments were conducted to explore neurocognitive effects of phobia-related stimuli. Contingency assessments and event-related potentials (ERPs) were collected from animal-fearful individuals during probabilistic classification learning in diverse motivational-affective contexts. As revealed by ERPs, attentional amplification of cortical sensory processing occurred in response to phobiarelated stimuli. In particular, the posterior selection negativity in the ERPs to phobia-related stimuli had its origin in a bottom-up route, probably the amygdaloid-extrastriate cortex path. No evidence for top-down modulation of phobia-related attentional amplification was obtained. The covariation bias occurred only when aversive motivational-affective expectancies prevailed, suggesting a role of retrieval from associative emotional memory. Finally, phobia-related cue competition was probably related to the disruption of elaboration in memory of neutral and aversive stimulus pairings that was induced by belonging pairings of phobia-related and aversive stimuli. The findings have far-reaching implications for the interface between cognition and emotion.
\end{abstract}

Emotions such as phobic fear have important signal functions that prompt the organism to selectively focus attention on particular attributes, stimuli, or events. Fear is a central motive state that activates defense behavior and associated emotional feelings (Lang, Davis, \& Öhman, 2000). Phobic fear may be defined as exaggerated fear that occurs in response to certain attributes, stimuli, or events in certain individuals (Fyer, 1998). The details of the neural and psychological mechanisms that link emotions like phobic fear and selective attention remain largely undisclosed. How does phobic fear guide selective attention? In two experiments, we examined the notion that phobic fear leads to amplified neural representations at the cortical level, a primary mechanism thought to implement selective attention (see below). Is there evidence that phobic fear is actually related to an amplification of sensory processing, or in other words, to attentional amplification in the sense of increased activity in cortical regions coding for phobia-related stimuli? For visually presented stimuli, the hypothesis of phobia-related attentional amplification would imply amplified activity in the portion of extrastriate cortex that represents phobia-related stimuli.

Encoding of emotional significance occurs very rapidly within the processing stream, in a "preattentive" stage

R.A. is now in Leipzig, Germany. This study was supported by Deutsche Forschungsgemeinschaft Grant KO 1239 and was based on R.A.'s doctoral dissertation. We thank those who kindly volunteered to participate in the study. Correspondence concerning this article should be addressed to B. Kopp, Municipal Hospital and Institute of Cognitive Neurology at the Technical University, Salzdahlumer Str. 90, 38126 Braunschweig, Germany (e-mail: b.kopp@klinikum-braunschweig.de). of processing that occurs prior to attentional selection, is relatively fast, and often occurs outside of or prior to conscious awareness (Compton, 2003; Öhman, 2000; Öhman $\&$ Mineka, 2001). For example, a growing number of behavioral (see, e.g., Öhman, Flykt, \& Esteves, 2001) and psychophysiological (e.g., Globisch, Hamm, Esteves, \& Öhman, 1999) studies indicate that animal-fearful individuals respond very rapidly to phobia-related stimuli. Moreover, numerous studies using a variety of paradigms have confirmed that emotionally relevant stimuli are likely to capture attention. The study of attentional bias toward emotional information has consistently emphasized the role of individual differences, and a large body of research has indicated that anxious individuals are more likely than controls to display attentional biases toward threatening information (Compton, 2003).

Neuroimaging studies have indicated that several areas of the visual association cortex are more strongly activated in response to emotionally arousing images, irrespective of their emotional valence (see, e.g., Lang, Bradley, \& Cuthbert, 1998). Other studies (Fredrikson, Wik, Annas, Ericson, \& Stone-Elander, 1995; Fredrikson et al., 1993) have revealed activation in the extrastriate cortex in response to phobia-related, in contrast with neutral, stimuli. These findings have been interpreted as indicating an attentional response toward emotionally arousing and phobia-related stimuli, respectively. Nonetheless, little is known about the exact quality of the modulation of sensory-perceptual cortical processing caused by phobia-related stimuli in animal-fearful individuals. Among the urgent questions is whether the modulation of sensory-perceptual processing 
occurs as part of either a bottom-up (i.e., probably subcorticocortical, as we will argue below) or a top-down (i.e., probably cortico-cortical; see below) route. The available neuroimaging studies have yielded divergent results: Whereas Johanson et al. (1998) reported overactive frontal areas in spider-phobic individuals during exposure to phobiarelated stimuli, Dilger et al. (2003) showed increased amygdala activation during presentation of phobia-related visual stimuli in spider phobics. Thus, to date, the issue of whether animal-fearful individuals mainly exhibit overactive subcortico-cortical (bottom-up) or cortico-cortical (top-down) pathways during exposure to phobia-related stimuli remains unresolved.

Sensory-perceptual cortical processes can also be studied in humans through noninvasive recordings of event-related brain potentials (ERPs; Hillyard, 1993). Selective attention usually exerts its effects on sensory-perceptual cortical processing during the first $200 \mathrm{msec}$ after stimulus onset. During this interval, elementary stimulus features are registered, and sensory inputs are either enhanced or suppressed by the brain's attention systems, according to their relevance. During the latter part of this interval, the coding of more complex features and feature conjunctions and the initial stages of pattern perception and object classification take place (see, e.g., Schendan, Ganis, \& Kutas, 1998). In studies in which very simple stimuli (light bars) were presented rapidly and unpredictably to the right and left visual fields, paying attention to the events in one field produced an amplitude enhancement of the early first positive peak ( $\mathrm{P} 1 ; 75-130 \mathrm{msec})$ and/or first negative peak $(\mathrm{N} 1 ; 150-190 \mathrm{msec})$ components elicited by those stimuli over the occipital scalp (Hillyard, Teder-Sälejärvi, \& Münte, 1998). When simple stimuli are attended on the basis of nonspatial features such as color, shape, spatial frequency, or orientation, the associated ERP components are qualitatively different from those seen during spatial attention. Stimuli having the attended value of one of these features elicit a selection negativity (SN) over the posterior scalp that begins at 140-180 msec and may last for $200 \mathrm{msec}$ (Harter \& Aine, 1984). The SN provides a measure of the selective processing of attended features: It is best observed in difference potentials in which the ERP elicited by a stimulus with an unattended feature value (e.g., a blue stimulus when red is attended) is subtracted from the ERP elicited by the same stimulus with the attended feature value (e.g., a blue stimulus when blue is attended). The neural generator of the SN is probably localized to the ventral extrastriate visual cortex (Martínez, Di Russo, Anllo-Vento, \& Hillyard, 2001). In addition, a selection positivity (SP) over the frontal scalp has been identified as accompanying the selection of these stimulus features (Kenemans, Kok, \& Smulders, 1993).

Emotional picture viewing studies are the typical ERP studies used for measuring the effects of emotional arousal on the sensory-perceptual cortical processing of visual stimuli (Lang et al., 1998). The results of such studies have suggested that electrical responses in cortical pathways of sensory, perceptual, and cognitive processing are modulated by emotion in humans (Carretié, MartinLoeches, Hinojosa, \& Mercado, 2001; Cuthbert, Schupp, Bradley, Birbaumer, \& Lang, 2000; Cuthbert, Schupp, Bradley, McManis, \& Lang, 1998; Kayser et al., 1997; Keil et al., 2002; Keil et al., 2001; Schupp et al., 2000). The studies converged to show a sustained late $(>300 \mathrm{msec})$ positive potential (LPP) with a focus over the parietal scalp in response to emotionally arousing - either pleasant or unpleasant_-pictures. In addition, ERPs to emotionally arousing pictures may be altered at earlier processing stages (Keil et al., 2003; Keil et al., 2001). ERPs in response to emotionally arousing pictures were associated with an early posterior negativity (EPN; Schupp, Junghofer, Weike, \& Hamm, 2003, 2004). Overall, these studies revealed modulations of the ERP as a function of the emotional arousal caused by visual stimuli, irrespective of their emotional valence. However, these studies have tended to confound emotional properties and some physical properties of pictures: Emotionally arousing pleasant pictures typically include family pictures or erotic images, emotionally arousing unpleasant pictures typically depict attack scenes or mutilation, and emotionally neutral pictures typically show household objects or mushrooms. Thus, in a manipulation of emotional arousal that is induced by pictures, the emotional qualities of the pictures are probably confounded with their physical disparities. Baas, Kenemans, Böcker, and Verbaten (2002) used an instructed fear paradigm in which safe cues and threat cues (predicting mild electrical shocks) were presented at a fast rate, and they found that the threat cues modulated exogenous sensory components, frontal SP, and parietal LPP.

The purpose of our two experiments was to explore neurocognitive effects of phobia-related stimuli by means of ERPs. We are unaware of any earlier study of the sensoryperceptual cortical effects of phobia-related stimuli as revealed by ERPs in animal-fearful individuals: Do phobiarelated stimuli exert effects on sensory-perceptual cortical processing that resemble the effects that we have described above of (spatial or feature-based) selective attention and/or of emotional arousal? Which psychological sequelae exist of attentional amplification of sensory-perceptual cortical processing caused by phobia-related stimuli?

\section{EXPERIMENT 1}

Attention in learning expresses itself across a number of species and across a variety of situations, in that more valid or more salient stimuli reduce learning about less valid or less salient stimuli. This cue competition in associative learning occurs not only when animals learn about associations between sensory and motivationally significant stimuli (Rescorla, 1988), but also when human learners assess the strength of relationships between occurrences of such stimuli (see, e.g., Kopp \& Wolff, 2000).

In this experiment, cue competition was considered in a modified form of multiple-cue probabilistic learning (MCPL). In order to describe MCPL, it is useful to define 
Table 1 Cue Validities in Experiments 1 and 2

\begin{tabular}{|c|c|c|c|c|c|c|}
\hline \multirow[b]{3}{*}{ Invalid Category } & \multicolumn{6}{|c|}{ Valid Category } \\
\hline & \multicolumn{2}{|c|}{ Instance 1} & \multicolumn{2}{|c|}{ Instance 2} & \multicolumn{2}{|c|}{ Totals } \\
\hline & Exp. 1 & Exp. 2 & Exp. 1 & Exp. 2 & Exp. 1 & Exp. 2 \\
\hline Instance 1 & $15 / 20$ & $16 / 20$ & $5 / 20$ & $4 / 20$ & $20 / 40$ & $20 / 40$ \\
\hline Instance 2 & $15 / 20$ & $16 / 20$ & $5 / 20$ & $4 / 20$ & $20 / 40$ & $20 / 40$ \\
\hline Totals & $30 / 40$ & $32 / 40$ & $10 / 40$ & $8 / 40$ & $40 / 80$ & $40 / 80$ \\
\hline
\end{tabular}

Note - Cell entries indicate the relative frequency of electrical shocks following the various cue combinations. See the text for an explanation.

the term stimulus validity. For instance, consider the example illustrated in Table 1. In this scenario, there are two dichotomous cue categories, termed the valid category and the invalid category. There are also two classes of outcomes, S (representing the electrical shock) and C (representing the pictorial representation of coins). Table 1 shows the frequency with which various cue combinations (e.g., Instance 1 of the valid category and Instance 1 of the invalid category) were presented and the frequency with which these cue combinations were followed by class S outcomes. For example, the top left cell of the table, which corresponds to a combination of Instance 1 of the valid category and Instance 1 of the invalid category, contains the expression " $15 / 20$," indicating that out of 20 occurrences of this particular cue combination, 15 resulted in outcome $S$ (hence, the remaining 5 resulted in outcome C).

The cell frequencies do not transparently indicate the overall base rate with which each outcome occurred nor the correlation of the outcomes with each cue category. Base rates and correlations can be gleaned from the marginal frequencies, computed by summing across rows and columns. The base-rate validity expresses the overall mean probability of outcome $\mathrm{S}$, which is .5 (or 40 out of 80 occurrences). Cue validities express deviations from the base rate: The probability of outcome $\mathrm{S}$ conditional on Instance 1 of the valid category is .75 (30 out of 40 occurrences), and the probability of outcome $\mathrm{S}$ conditional on Instance 2 of the valid category is .25 (10 out of 40 occurrences). These conditional probabilities deviate 25 percentage points from the base rate. Hence, the valid category has a validity of .25 . In contrast, the probability of outcome S conditional on Instance 1 of the invalid category is .5 ( 20 out of 40 occurrences), and the probability of outcome S conditional on Instance 2 of the invalid category is again .5 (20 out of 40 occurrences). These conditional probabilities do not deviate from the base rate, so the invalid category has zero validity. Kruschke and Johansen (1999) showed that increasing the validity of one cue in the MCPL paradigm decreased the utilization of another cue (i.e., the classic cue competition phenomenon). Moreover, even the addition of a completely invalid cue decreased the utilization of a valid cue. Most importantly, the deleterious influence of such an invalid cue depended on its salience, because a valid cue was utilized even less when highly salient rather than less salient invalid cues were used.
Kopp, Altmann, and Hermann (2003) analyzed MCPL in spider-fearful individuals. Pictures of household goods formed the valid category, whereas pictures of spiders represented the invalid category. On any trial, the participant saw a combination of two cues, guessed the upcoming outcome, and finally received an electrical shock or a pictorial representation of coins (confirming or disconfirming the current guess). Participants had to glean which outcome tended to go with which cue, and they were asked to assess the cue-outcome contingencies after series of trials. Invalid pairings of phobia-related and aversive stimuli exerted competitive effects on the accruing of associative strength between neutral and aversive stimuli in spider-fearful individuals (phobia-related cue competition). Similar findings had been obtained in a study that investigated the role of belongingness, a concept that is often used to explain the better fear conditionability in healthy individuals of stimulus pairings that engage similar motivational-affective systems (Hamm, Vaitl, \& Lang, 1989).

Other psychological models of phobic fear have postulated that the development and/or the maintenance of phobic fear is related to the existence of illusory correlations between phobia-related and aversive stimuli (Tomarken, Mineka, \& Cook, 1989). The term covariation bias refers to the tendency, after a series of trials, to perceive higher contingencies between phobia-related and aversive stimuli in comparison with neutral and aversive stimuli (see, e.g., Tomarken et al., 1989; Tomarken, Sutton, \& Mineka, 1995). It has been suggested that covariation bias might be mediated by confirmatory cognitive processes, in that pairings of phobia-related and aversive stimuli are processed more extensively, leading to the progressive augmentation of the subjective strength of their association (Tomarken et al., 1989).

Experiment 1 was conducted to investigate whether phobia-related cue competition in MCPL (see above) is replicable or not. If so, phobia-related cue competition could be traced back to phobia-related attentional amplification. To examine the attentional hypothesis of phobiarelated cue competition, sensory-perceptual ERP measures were collected during the modified MCPL paradigm to identify possible effects of phobia-related stimuli that might resemble known effects of (either spatial or featurebased) selective attention and/or of emotional arousal on ERPs. Participants with either exaggerated fear of spiders and little fear of snakes or exaggerated fear of snakes and little fear of spiders were recruited. The key variable was the phobia relatedness of two categories of animal pictures. For the groups of spider/snake-fearful individuals, respectively, spiders/snakes were the phobia-related stimuli, whereas snakes/spiders were phobia-unrelated stimuli. Thus, the effects of phobia relatedness could be examined by comparing ERPs to phobia-unrelated stimuli (e.g., ERPs to spiders obtained from snake-fearful individuals) with those to physically identical but phobia-related stimuli (e.g., ERPs to spiders obtained from spider-fearful individuals), and finally collapsing the results over all ERPs to spiders and all ERPs to snakes. Note that although the 
phobia relatedness of stimuli were manipulated in this comparison, their physical appearance was kept constant. Under this experimental design, the effects of phobia relatedness should be detectable as a statistical interaction (phobia group $\times$ animal category).

\section{Method}

\section{Participants}

A total of 32 paid ( $€ 25)$ young females participated. The participants were recruited by advertisements posted on bulletin boards for students. The participants were not treated by anxiolytic drugs, nor by psychological therapy. After a brief diagnostic screening by phone, the participants were invited for clinical assessment. All participants completed the following questionnaires designed for assessing the level of fear of spiders and snakes, respectively: the German versions of the spider questionnaire (SPQ) and the snake questionnaire (SNAQ) (Globisch et al., 1999; Klorman, Weerts, Hastings, Melamed, \& Lang, 1974). Participants were included in the spider-fearful group if they scored above 17 in the SPQ and below 9 in the SNAQ or in the snake-fearful group if they scored above 16 in the SNAQ and below 9 in the SPQ.

All participants underwent the structured clinical diagnostic interview (SCID; German adaptation: Wittchen, Zaudig, \& Fydrich, 1997) to ascertain DSM-IV diagnoses of spider phobia or snake phobia, respectively, and were screened for other Axis I disorders. In addition, their level of depression was assessed with a German adaptation of the CES depression scale (Hautzinger \& Bailer, 1993). Participants were excluded if a current episode of major depression or any other Axis I disorder was diagnosed. Twelve (8) of the 16 spider/snake-fearful participants, respectively, met the DSM-IV criteria for spider or snake phobia, and the remaining 4 (8) participants met all of the DSM-IV criteria except being significantly impaired in their daily functioning.

The two groups were similar in age (spider-fearful group, $M=$ 22.3 years, $S D=2.1$; snake-fearful group, $M=25.9$ years, $S D=5.6$ ), and there was no difference with respect to their level of education (14 university students were in each group). As expected, spider-fearful individuals had higher SPQ scores than did snake-fearful individuals (spider-fearful group, $M=22.3, S D=2.8$; snake-fearful group, $M=3.6, S D=1.9$ ), and snake-fearful individuals had higher SNAQ scores than did spider-fearful individuals (snake-fearful group, $M=$ 23.3, $S D=3.1$; spider-fearful group, $M=5.5, S D=2.4$ ). Level of depression did not differ between the groups (spider-fearful group, $M=9.7, S D=5.2$; snake-fearful group, $M=11.8, S D=5.2)$. All participants gave informed consent after the nature of the study and possible consequences had been explained.

\section{Stimuli}

Four categories of objects were used as cues: pictures of spiders, snakes, chairs, and household goods. The pictures of spiders and snakes are documented in Figure 1. Depending on the group membership of the individual participants, spiders or snakes were phobiarelated or -unrelated stimuli. Chairs and household objects (a book or a clothes basket) served as neutral stimuli. All pictures were presented (size: $30 \times 22 \mathrm{~cm}$ ) in color against a black background on a 19-in. cathode ray tube (CRT) connected to a Pentium PC. The outcome stimulus was either an electrical shock (aversive, category $\mathrm{S}$ outcome) or a pictorial presentation of coins (appetitive, category $\mathrm{C}$ outcome). The electrical shock was administered by a Toennies shock generator (range, 1-10 mA; www.jaeger-toennies.com/index .html) to the hypothenar eminence of the nondominant hand. Its amplitude was individually adjusted and was $7 \mathrm{~mA}$ on average. The electrical shock had a duration of $10 \mathrm{msec}$; the pictorial presentation of coins lasted $500 \mathrm{msec}$. The electrical shock was subjectively rated as unpleasant but nonpainful.

\section{Procedure}

Each trial started with the presentation of two cues, one after the other. Each cue was presented for $1,000 \mathrm{msec}$, with a stimulus onset asynchrony of 2,500 msec. A picture of an animal (a spider or snake) and a picture of a chair or household good were always combined within one trial. The sequential order of the two categories of pictures and the particular combination of categories were balanced across individuals. Thus, spiders or snakes were either combined with chairs or with household goods, but all possible combinations occurred equally often within each group of participants. After the

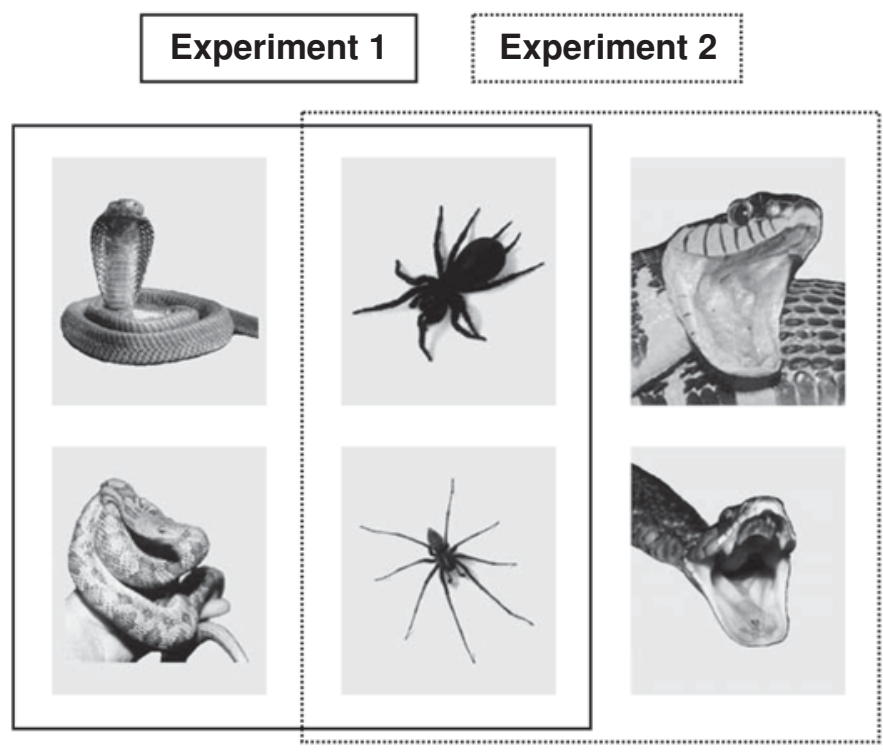

Figure 1. The pictures of spiders and snakes that were utilized in Experiment 1 (left side, in solid frame) and Experiment 2 (right side, in dotted frame). 
offset of the second cue, the participants predicted the upcoming outcome by pressing a response key. One was labeled shock (pressed by the left index finger), and the other was labeled coins (pressed by the right index finger). There was no time pressure for the execution of this response. The actual trial outcome was presented $1,000 \mathrm{msec}$ after the participant's response. The intertrial interval was $2,000 \mathrm{msec}$.

The experiment totaled 480 trials, which were divided into six blocks of 80 trials apiece. Table 1 displays the contingencies that were used within each block of trials. Animal pictures served in all blocks as the invalid category, and pictures of chairs or household goods always represented the valid category. Each block of trials contained only one category of invalid stimuli (spiders or snakes) and only one category of valid stimuli (chairs or household objects), and both instances from each category (see Figure 1) were used within each block. The assignment of outcome $\mathrm{S}$ or $\mathrm{C}$ to particular instances of the stimuli was balanced across individuals. The sequence of trials within a block was randomized.

The key variable that was manipulated was the phobia relatedness of the invalid category. Throughout three successive blocks of trials, the invalid category consisted of either phobia-related or -unrelated pictures for the participant's particular group. The order of the three blocks of phobia-related versus -unrelated trials was balanced across individuals.

The experiment began with a practice block, which consisted of 40 trials in which pictorial representations of landscapes were used as cues. These pictures were taken from the International Affective Picture System (IAPS; Bradley, Greenwald, Petry, \& Lang, 1992). After the initial practice block, the participants assessed the cue-outcome contingencies a first time to familiarize them with this task.

Written instructions to the participants read as follows:

This experiment examines probabilistic category learning. There will be a practice block of trials and six additional blocks of trials. Two stimuli (pictures of objects) are presented in each trial, which are followed by an outcome that is either a mild electrical shock or a pictorial presentation of coins

Your task is to guess - after the offset of both stimuli - the identity of the upcoming outcome that correlates with the identity of some of the stimuli. You can do this by pressing one of two response keys. The actual outcome will appear $1 \mathrm{sec}$ after your keypress. The contingencies between stimuli and outcomes are constant within blocks of trials. They do not depend upon the pattern of your keypresses. After each block of trials, you will have to rate the extent to which stimuli and outcomes were related.

The participants were tested individually. The shock electrode and the electrodes necessary to record the electroencephalogram (EEG) and the electrooculogram (EOG) were attached. They sat in a comfortable chair in a sound-attenuated, dimly lit room at a distance of $160 \mathrm{~cm}$ from the CRT. The timing of the stimuli and the identification of the keypresses were performed by a Turbo-Pascal computer program.

\section{Measures}

Behavioral measures. Emotional valence and arousal were assessed for all cues and outcome stimuli before MCPL started. Valence and arousal assessments were obtained on rating scales ranging from 1 (pleasant) to 9 (unpleasant) and 1 (not arousing) to 9 (highly arousing), respectively.

After each block of trials, subjective contingencies between cues and outcomes were assessed. These ratings were prompted by four questions that read as follows:

$$
\begin{aligned}
& \text { If instance "X" }[1 \text { or } 2] \text { of cue "Y" [ } \text { valid category or invalid category }] \\
& \text { was present, how probable was } \\
& \quad \rightarrow \text { the "shock" } \\
& \rightarrow \text { the "coins" }
\end{aligned}
$$

The participants were reminded on each sheet of this questionnaire that the sum of these two ratings should equal 100 (i.e., they were asked for percentage ratings). Overall, the participants judged eight conditional probabilities - that is, all $P[$ outcome $(Z)$, valid category $(X)]$ and $P[\operatorname{outcome}(Z)$, invalid category $(X)]$, where $Z$ stands for either the shock or coins outcome.

From these ratings, contingency judgments were calculated for each participant and each block of trials by calculating the mean ratings

$$
\frac{P(O=\text { shock } / \text { Valid } C=I 1)+[100-P(O=\text { shock } / \text { Valid } C=I 2)]}{2}
$$

and

$$
\frac{P(O=\text { shock } / \text { Invalid } C=I 1)+P(O=\text { shock } / \text { Invalid } C=I 2)}{2},
$$

respectively, where $O$ is the outcome, $C$ is the category, and $I$ is the instance. These contingency judgments correspond to a subjective estimate of the proportions equivalent to the marginal frequencies presented in Table 1: The objective contingency between the invalid category and the shock outcome is equal to $(50 \%$ [or $20 / 40]+50 \%$ $[20 / 40]) / 2=50 \%$ (see the marginal row frequencies), whereas the objective contingency between the valid category and the shock outcome is $\{75 \%[30 / 40]+(100-25 \%[10 / 40])\} / 2=75 \%$ (see the marginal column frequencies).

Electrophysiological recording and analysis. The EEG was continuously recorded according to the international 10-20 system using Sn electrodes mounted on a cap. The EEG was amplified by a 32-channel SynAmps amplifier (NeuroScan Compumedics; www .neuro.com/index.sstg). Linked mastoids served as reference. The EEG was DC recorded and low-pass filtered at a cutoff frequency of $100 \mathrm{~Hz}$. The EEG was digitized at a sampling rate of $500 \mathrm{~Hz}$. Electrode impedance was kept below $5 \mathrm{k} \Omega$. Vertical and horizontal EOGs were recorded from above and below the left eye and from $1 \mathrm{~cm}$ external to the outer canthus of each eye. The continuous EEG was cut into epochs $600 \mathrm{msec}$ in duration. The epochs were time locked to the onset of the cues, starting $100 \mathrm{msec}$ before and ending $500 \mathrm{msec}$ after cue onset. EEG epochs were baseline corrected, with the interval starting at $100 \mathrm{msec}$ before onset and ending with the onset of the stimuli. Trials containing horizontal eye movements were rejected; trials containing blinks were corrected using the regression method described by Berg (1986). After stimulustriggered averaging, the ERPs were transformed to an average reference (Picton et al., 2000). The peak amplitudes of (1) the P1 in the latency range from $80-130 \mathrm{msec}$ after stimulus onset at occipital electrodes $\mathrm{O}_{1}$ and $\mathrm{O}_{2}$ and (2) the $\mathrm{N} 1$ in the latency range from $110-180 \mathrm{msec}$ at temporal electrodes $\mathrm{T}_{5}$ and $\mathrm{T}_{6}$ were quantified. The anterior SP was quantified as the mean amplitude in the latency range from 160-230 msec after stimulus onset at frontal electrodes $\mathrm{F}_{3}, \mathrm{~F}_{\mathrm{z}}$, and $\mathrm{F}_{4}$. The posterior $\mathrm{SN}$ was quantified as the mean amplitude in the latency range from $175-275 \mathrm{msec}$ after stimulus onset at occipital electrodes $\mathrm{O}_{1}$ and $\mathrm{O}_{2}$. Finally, the LPP was quantified as the mean amplitude in the latency range from $400-500 \mathrm{msec}$ after stimulus onset at the parietal electrode, $\mathrm{P}_{\mathrm{z}}$.

\section{Results}

\section{Ratings of Emotional Valence and Arousal}

The results that were obtained from spider-fearful and snake-fearful individuals are displayed in Table 2. As expected, the phobia-related pictures achieved more negative ratings of emotional valence and arousal than did the phobia-unrelated pictures of animals in both groups of participants. Apart from this phobia-specific response pattern, the two groups of participants displayed comparable emotional responses to the pictures of all neutral stimuli (chairs or household objects), shocks, and coins. Neutral stimuli generally elicited medium ratings of 
Table 2

Emotional Valence and Arousal Associated With All Stimuli in Experiment 1

Valence

Arousal

$\overline{\text { Spider Fearful Snake Fearful }} \overline{\text { Spider Fearful Snake Fearful }}$

\begin{tabular}{|c|c|c|c|c|c|c|c|c|}
\hline & & & & & & \\
\hline$\underline{\text { Stimuli }}$ & \multicolumn{2}{|l|}{$M$} & $M$ & $S D$ & $M$ & $S D$ & $M$ & $S D$ \\
\hline Spider 1 & 8.8 & 0.5 & 5.6 & 1.2 & 7.7 & 1.3 & 3.1 & 1.5 \\
\hline Spider 2 & 8.6 & 0.5 & 5.5 & 1.0 & 7.2 & 0.9 & 2.6 & 1.3 \\
\hline Snake 1 & 5.3 & 1.0 & 8.4 & 0.8 & 2.9 & 1.4 & 6.6 & 2.0 \\
\hline Snake 2 & 5.2 & 0.8 & 8.6 & 0.7 & 3.1 & 1.6 & 6.1 & 2.1 \\
\hline Chair 1 & 4.1 & 1.3 & 3.8 & 1.2 & 1.3 & 1.0 & 1.6 & 1.6 \\
\hline Chair 2 & 4.6 & 1.0 & 3.8 & 1.3 & 1.3 & 1.0 & 1.6 & 1.2 \\
\hline Book & 3.5 & 1.4 & 3.9 & 1.3 & 1.5 & 0.9 & 1.9 & 1.5 \\
\hline Basket & 4.5 & 1.0 & 4.2 & 1.3 & 1.2 & 0.8 & 1.4 & 1.3 \\
\hline Coins & 2.5 & 1.0 & 2.1 & 0.7 & 3.4 & 1.5 & 4.0 & 2.1 \\
\hline Shock & 7.1 & 0.4 & 7.1 & 0.8 & 4.4 & 1.6 & 5.0 & 1.9 \\
\hline
\end{tabular}

Note-The highest $M$ of a group of participants is presented in boldface; the lowest $M$ of a group of participants is italicized. Valence and arousal assessments were obtained on rating scales ranging from 1 (pleasant) to 9 (unpleasant) and 1 (not arousing) to 9 (highly arousing), respectively.

Table 3

Contingency Ratings (\%) in Experiment 1

\begin{tabular}{|c|c|c|c|c|}
\hline \multirow[b]{2}{*}{ Stimuli } & \multicolumn{2}{|c|}{ Spider Fearful } & \multicolumn{2}{|c|}{ Snake Fearful } \\
\hline & $M$ & $S D$ & $M$ & $S D$ \\
\hline \multicolumn{5}{|l|}{ Pictures of animals } \\
\hline Spiders & 52.0 & 14.6 & 50.3 & 8.4 \\
\hline Snakes & 51.1 & 11.1 & 53.0 & 12.8 \\
\hline \multicolumn{5}{|l|}{ Pictures of objects } \\
\hline Spiders accompanying & 66.4 & 11.9 & 73.3 & 11.0 \\
\hline Snakes accompanying & 73.4 & 13.9 & 62.1 & 15.9 \\
\hline
\end{tabular}

Note-Actual contingencies were $50 \%$ for pictures of animals and $75 \%$ for pictures of objects.

emotional valence and low ratings of emotional arousal. Coins/shocks were associated with positive/negative ratings of emotional valence, respectively, and with medium ratings of emotional arousal.

\section{Contingency Ratings}

Mean ratings of contingencies between cues and shock outcomes that were obtained from spider-fearful and snake-fearful individuals are displayed in Table 3. The ratings of the contingencies between animal pictures and shocks were analyzed using an ANOVA with the factors group (spider fearful, snake fearful), animal category (spider, snake), and block of trials (first, second, third). The ANOVA revealed no effect that reached statistical significance, with the sole exception of the animal $\times$ block interaction $\left[F(2,60)=4.7, M S_{\mathrm{e}}=77.3, \omega^{2}=0.11\right.$, $p<.05]$. The group $\times$ animal interaction clearly failed to reach significance $[F(1,30)<1]$, suggesting that no covariation bias was evoked in this experiment. Contingency ratings between neutral pictures and shocks were analyzed via an ANOVA with the factors group (spider fearful, snake fearful), accompanying animal category (spider, snake), and block of trials (first, second, third). Here, only the group $\times$ animal interaction proved signifi- cant $\left[F(1,30)=10.4, M S_{\mathrm{e}}=379.7, \omega^{2}=0.23, p<.01\right]$. Inspection of Table 3 reveals that this interaction was due to reduced ratings of the contingencies between neutral pictures and shocks when the neutral pictures were accompanied by phobia-related rather than -unrelated pictures of animals; that is, there was a phobia-related cue competition effect.

\section{Event-Related Brain Potentials}

P1 and N1. Figure 2 depicts the ERPs that were obtained in response to phobia-related versus -unrelated pictures of animals across the scalp. At posterior electrodes, the waveforms are dominated by a P1 at occipital electrodes as well as an N1 at occipito-temporal electrodes. An ANOVA for the peak amplitude of the P1 at occipital electrodes [with the factors phobia group (spider fearful, snake fearful), animal category (spiders, snakes), and electrode position $\left(\mathrm{O}_{1}, \mathrm{O}_{2}\right)$ ] revealed a significant animal $\times$ electrode interaction $\left[F(1,30)=9.5, M S_{\mathrm{e}}=\right.$ $\left.0.8, \omega^{2}=0.21, p<.01\right]$, indicating that snake pictures showed a larger $\mathrm{O}_{2}$ prominence than did spider pictures. An ANOVA for the peak amplitude of the N1 at temporal electrodes [phobia group (spider fearful, snake fearful) $\times$ animal category (spiders, snakes) $\times$ electrode position $\left.\left(\mathrm{T}_{5}, \mathrm{~T}_{6}\right)\right]$ revealed a significant main effect of animal $\left[F(1,30)=29.7, M S_{\mathrm{e}}=5.0, \omega^{2}=0.47, p<.01\right]$, indicating that spider pictures led to more pronounced N1 peaks than did snake pictures.

SP and SN. Figure 3 depicts the SP at the frontal electrodes, and Figure 4 depicts the $\mathrm{SN}$ at the occipital electrodes. Inspection of the difference waves in Figure 3 reveals that the SP is a frontally positive deflection (less than $+1 \mu \mathrm{V}$ ) of the ERP in response to phobiarelated rather than -unrelated animals that peaks at around $200 \mathrm{msec}$ after stimulus onset. Similarly, inspection of the difference waves in Figure 4 reveals that the SN is a negative deflection at the occipital electrodes (less than $-2 \mu \mathrm{V}$ ) of the ERP in response to phobia-related rather than -unrelated animals and that it peaks at around $200 \mathrm{msec}$ after stimulus onset. An ANOVA for the mean amplitude of the SP at frontal electrodes [phobia group (spider fearful, snake fearful) $\times$ animal category (spiders, snakes) $\times$ electrode position $\left(\mathrm{F}_{3}, \mathrm{~F}_{\mathrm{z}}, \mathrm{F}_{4}\right)$ ] revealed a significant main effect of animal $\left[F(1,30)=15.0, M S_{\mathrm{e}}=3.5, \omega^{2}=0.31\right.$, $p<.01]$ and a significant group $\times$ animal interaction $\left[F(1,30)=4.5, M S_{\mathrm{e}}=3.5, \omega^{2}=0.10, p<.05\right]$. Thus, the indicated modulation of the ERP by the phobia relatedness of animal pictures at the frontal electrodes in the latency range from 160-230 msec after stimulus onset (Figure 3 ) proved to be statistically reliable. A similar pattern of results was obtained from an ANOVA for the mean amplitude of the SN at the occipital electrodes [phobia group (spider fearful, snake fearful) $\times$ animal category (spiders, snakes) $\times$ electrode position $\left(\mathrm{O}_{1}, \mathrm{O}_{2}\right)$ ]. Besides a significant animal main effect $\left[F(1,30)=8.1, M S_{\mathrm{e}}=\right.$ $\left.8.6, \omega^{2}=0.18, p<.01\right]$, the group $\times$ animal interaction also proved significant $\left[F(1,30)=6.6, M S_{\mathrm{e}}=8.6, \omega^{2}=\right.$ $0.15, p<.05]$, indicating that the modulation of the ERPs 


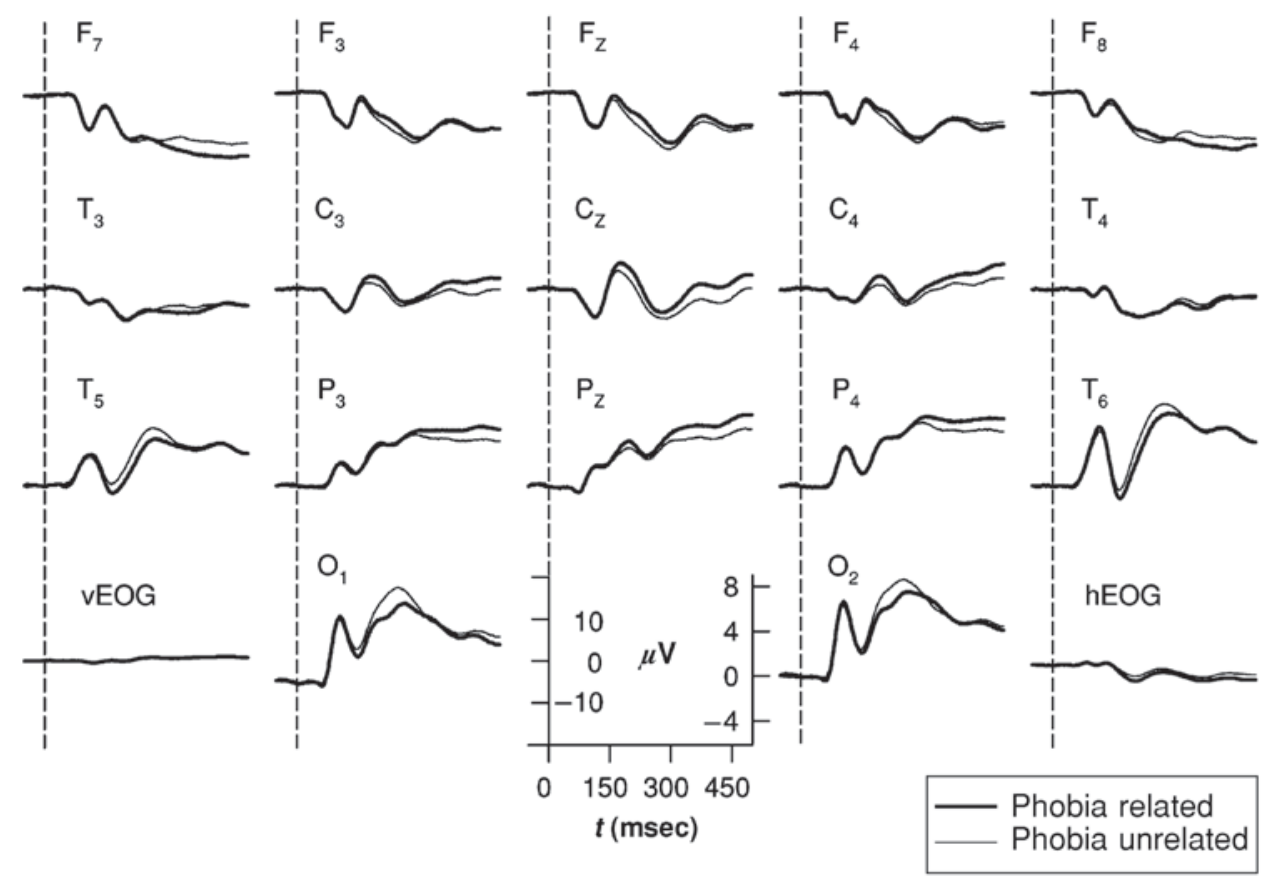

Figure 2. Grand average event-related potential (ERP) waveforms elicited by phobia-related and -unrelated pictures of animals in Experiment 1. Stimulus onset was at $\boldsymbol{t}=\mathbf{0}$. Scaling on the left corresponds to the electrooculogram (EOG); scaling on the right is for the ERP. vEOG, vertical EOG; hEOG, horizontal EOG.

by the phobia relatedness of animal pictures at the occipital electrodes in the latency range from $175-275 \mathrm{msec}$ after stimulus onset (Figure 4) was statistically reliable.

LPP. Finally, the mean amplitude in the latency range from $400-500 \mathrm{msec}$ after stimulus onset at parietal elec- trode $\mathrm{P}_{z}$ (see Figure 2) was fed in statistical analysis. The ANOVA for the LPP [phobia group (spider fearful, snake fearful) $\times$ animal category (spiders, snakes)] revealed a significant group $\times$ animal interaction $[F(1,30)=9.0$, $\left.M S_{\mathrm{e}}=2.4, \omega^{2}=0.2, p<.01\right]$, indicating that like the SP
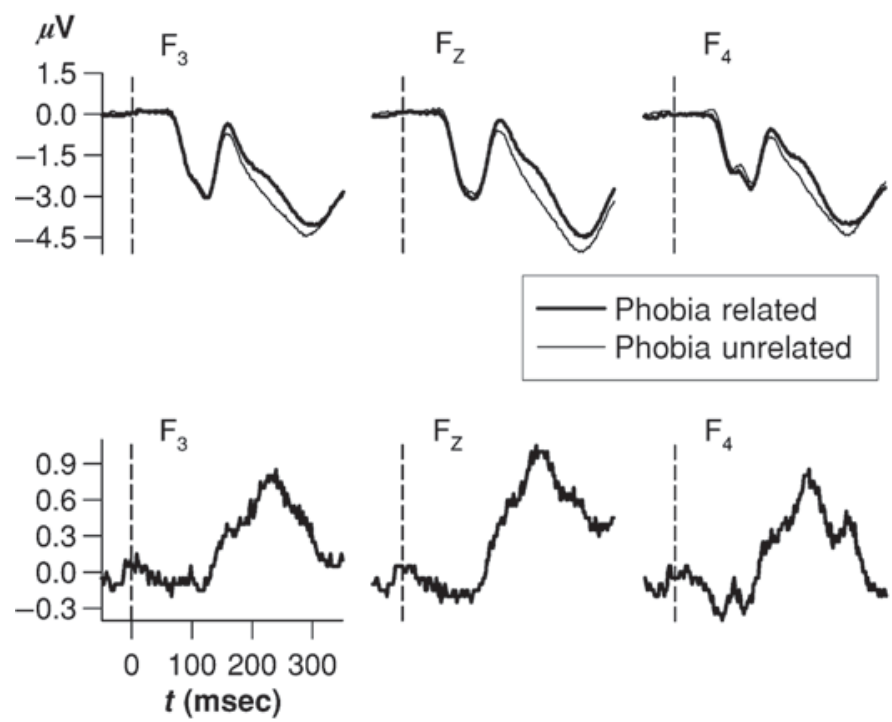

Figure 3. (Upper panel) Frontal grand average event-related potential (ERP) waveforms elicited by phobia-related and -unrelated pictures of animals in Experiment 1. (Lower panel) Difference waves obtained by subtracting the ERP for phobia-unrelated stimuli from that for phobiarelated stimuli. Stimulus onset was at $t=0$. 


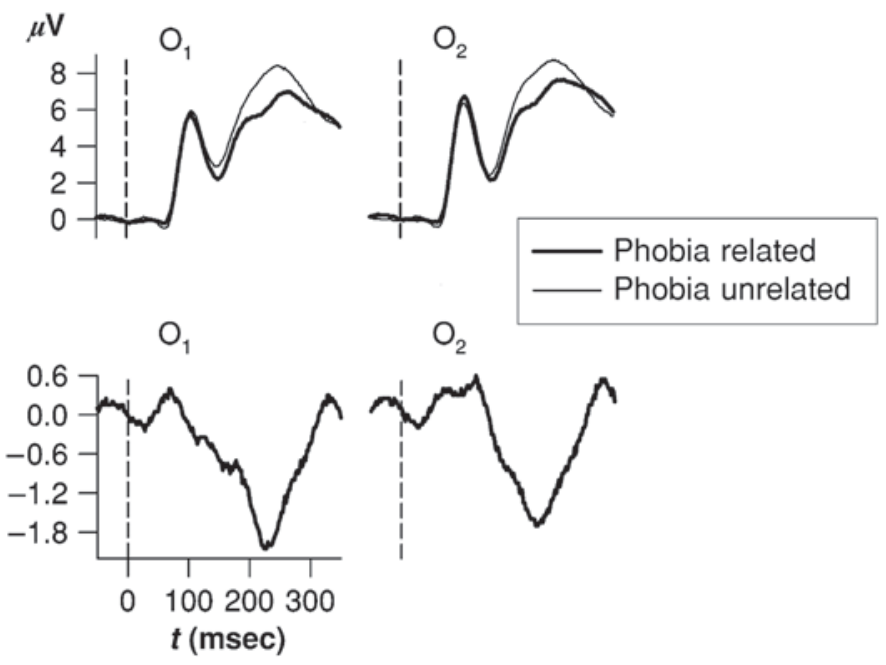

Figure 4. (Upper panel) Occipital grand average event-related potential (ERP) waveforms elicited by phobia-related and -unrelated pictures of animals in Experiment 1. (Lower panel) Difference waves obtained by subtracting the ERP for phobia-unrelated stimuli from that for phobiarelated stimuli. Stimulus onset was at $t=0$.

and the SN, LPP was modulated by the phobia relatedness of animal pictures.

\section{Discussion}

This MCPL experiment found several neurocognitive effects of phobia-related stimuli in animal-fearful individuals. To begin with, the phobia-related effects on the contingency ratings replicated those of an earlier study (Kopp et al., 2003). In particular, animal-fearful individuals did not overestimate the contingencies between phobia-related and aversive stimuli. However, whereas no covariation bias was evoked, pairings of phobia-related and aversive stimuli did exert competitive effects on the accruing of associative strength between neutral and aversive stimuli. Thus, the phenomenon of phobia-related cue competition is a replicable phenomenon in MCPL, and similar findings have been documented in studies of fear conditioning (Hamm et al., 1989).

The ERP results provide insight into the neural correlates of phobia-related cue competition. First, the phobiarelated effects on the anterior SP as well as the posterior SN are highly reminiscent of the effects of nonspatial feature-based visual attention on ERPs, thus supporting the attentional amplification hypothesis. Second, the posterior SN bears resemblance to the EPN in response to emotionally arousing pictures that was described by Schupp et al. (2003, 2004). Because the posterior SN probably originates from neurons in the extrastriate visual cortex (Martínez et al., 2001), the phobia-related modulation of the SN probably reflects amplified activity in the portion of extrastriate cortex that represents phobiarelated stimuli. This phobia-related attentional amplification is obviously based on preferential processing of yet unknown features of phobia-related stimuli in animalfearful individuals, since phobia-related modulation of the SN resembles the effects of feature-based visual attention rather than of spatial visual attention. Taken together, the emerging link between phobia-related stimuli and involuntary capture of feature-based visual attention lends support to the hypothesis that phobia-related cue competition can possibly be traced back to phobia-related attentional amplification.

Much less can be said about the importance of the phobia-related effect on the anterior SP and on the LPP. With regard to the SP, it remains to be delineated whether the SP is a reflection of independent electrical activities at frontal electrodes or merely a mirroring of the posterior SN. As was noted in the Method section, the 32-channel EEG was transformed offline into an average reference, and this otherwise preferable reference scheme (Picton et al., 2000) is susceptible to this kind of mirroring (Hagemann, Naumann, \& Thayer, 2001). As for the LPP, the specificity of its modulation by the aversive motivational system is highly questionable, because the amplitude of the LPP varies as a function of the emotional arousal that is elicited by a picture but is independent of the emotional valence associated with the picture.

\section{EXPERIMENT 2}

The ERP results obtained in Experiment 1 yielded evidence for phobia-related attentional amplification of sensory-perceptual processing in the extrastriate visual cortex. How is this amplification process initiated? What mechanism(s) cause(s) visual cortical areas to become more active when they are representing phobia-related stimuli? One possibility is that subcortico-cortical projections from the amygdala to sensory cortex may contribute to the amplification of cortical representations. The amygdala is known to have reciprocal connections with 
cortical sensory areas (Amaral, Price, Pitkanen, \& Carmichael, 1992), and the amygdala is an important structure in the initial encoding of emotional significance (Davis, 1992; Kalin, Shelton, \& Davidson, 2004; LeDoux, 2000). Thus, one likely mechanism for attentional amplification is that when the amygdala detects an emotionally significant stimulus, it sends a modulating signal to the cortical areas responsible for building a detailed representation of that stimulus.

Whereas the amygdala can send bottom-up influences that amplify phobia-related cortical representations, corticocortical processes may act in a top-down fashion to modulate the processing of phobia-related information. In particular, the dorsolateral region of the prefrontal cortex is involved in imposing top-down control that selects and maintains task-relevant representations originating from other areas of the brain, thus imposing attentional sets for adequate flexibility in behavior (see, e.g., Miller \& Cohen, 2001). Prefrontal regions also have the ability to select for emotionally relevant information (Compton, 2003), and the reciprocal connections between the amygdala, sensory cortical areas, and frontal lobe control regions create a recursive loop in which the evaluation of emotional relevance can be influenced by higher order goals, just as higher order goals can be modified as new information about current events becomes available. Thus, phobiarelated attentional amplification possibly involves a combination of bottom-up and top-down influences on sensory areas that represent the phobia-related information.

Experiment 1 made use of outcome stimuli that engaged the aversive motivational-affective system as well as the appetitive motivational-affective system. Under these conditions, the setting of higher order goals may be biased by neither aversive nor appetitive motivational-affective states. In contrast, the introduction of purely aversive or purely appetitive motivational-affective conditions may bias the setting of higher order goals toward goals that are compatible with either aversive states (withdrawal) or appetitive states (approach), respectively. Davidson (2003) provides a comprehensive review of the functional neuroanatomy of approach and withdrawal, including the essential role of prefrontal regions. To the degree that the setting of higher order goals hinges on new information about current events, the manipulation toward aversive versus appetitive motivational-affective states should affect phobia-related attentional amplification and/or phobia-related cue competition. In addition, Experiment 2 provided an occasion for examining the replicability of phobia-related attentional amplification and/or cue competition under slightly modified conditions.

\section{Method}

\section{Participants}

The recruitment of participants was identical to that for Experiment 1 . Thirty-two paid $(€ 25)$ young females participated. Eight (10) of the 16 spider/snake-fearful participants, respectively, met the DSM-IV criteria for spider/snake phobia, and the remaining 8 (6) participants met all DSM-IV criteria except being significantly impaired in their daily functioning. The two groups were similar in age (spider-fearful group, $M=23.4$ years, $S D=5.1$; snakefearful group, $M=25.1$ years, $S D=7.9$ ), and there was no major difference with respect to their level of education (16 university students in the spider-fearful group; 13 university students in the snake-fearful group). As expected, spider-fearful individuals had higher SPQ scores than did snake-fearful individuals (spider-fearful group, $M=20.5, S D=2.2$; snake-fearful group, $M=3.5, S D=$ 1.7), and snake-fearful individuals had higher SNAQ scores than did spider-fearful individuals (snake-fearful group, $M=21.4, S D=$ 2.4; spider-fearful group, $M=2.6, S D=2.2$ ). Level of depression did not differ between the groups (spider-fearful group, $M=13.6$, $S D=7.3$; snake-fearful group, $M=10.6, S D=6.3$ ). All participants gave informed consent after the nature of the study and possible consequences had been explained.

\section{Stimuli and Procedure}

These were similar to those in Experiment 1, with the modifications described below. Figure 1 depicts the animal pictures that were used in Experiment 2. The snake pictures differed across the two experiments, but the spider pictures were kept constant. The new snake pictures were selected in an attempt to enhance their emotional arousal for snake-fearful individuals (cf. Tables 2 and 4). Pictures of human faces instead of pictures of chairs and household objects served as neutral stimuli in order to explore the generalizability of phobia-related cue competition across various categories of stimuli (objects or human faces). Four pictures of male faces and four pictures of female faces were taken from the picture series in Mazurski and Bond (1993). Female and male faces were always combined with pictures of spiders or snakes, respectively. The trials were presented in two conditions differing with respect to the motivational quality of the outcomes. In the aversive motivational context, the pictures were either followed by an electrical shock or by no outcome stimulus within a trial. In the appetitive motivational context, the pictures were either followed by a picture of coins or by no outcome stimulus. The participants received the information that their allowance for participation (which started at a baseline of $€ 17)$ increased by $€ 0.05$ each time the picture of coins appeared in the experiment ( 2 blocks $\times 80$ trials $\times € 0.05=€ 8$ ). Two faces from each sex were used in two consecutive blocks of trials that constituted a motivational context, and the remaining two faces from that sex were used in the next two blocks of trials that formed the alternative motivational context. The sequential orders of the categories of animal pictures, of the two motivational contexts, and of the particular combination of faces and motivational contexts were balanced across individuals.

The cues were presented for $500 \mathrm{msec}$, with a stimulus onset asynchrony of $1,700 \mathrm{msec}$. The presentation of the pictures of coins lasted $250 \mathrm{msec}$. The trial outcome was presented $500 \mathrm{msec}$ after the participant's response. The experiment totaled 640 trials, which were divided into eight blocks $(2$ animal categories $\times 2$ motivational contexts $\times 2$ repetitions) of 80 trials each. The contingencies between cues and outcomes within a block of trials were slightly modified (see Table 1): This time, the base rate of outcome $\mathrm{S}$ (or $\mathrm{C}$, respectively) was $50 \%$, the validity of the valid category (faces) was $30 \%$, and the validity of the invalid category (animals) was zero.

\section{Measures}

Behavioral measures. These were nearly identical to those in Experiment 1. In the aversive motivational context, in which cueshock ratings were analyzed, the prompts for the contingency ratings had the following form:

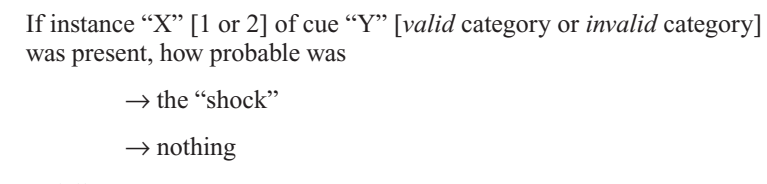

to follow? 
In the appetitive motivational context, the term shock was replaced with coins, and cue-coins ratings were analyzed.

Electrophysiological recording and analysis. These were nearly identical to the procedures in Experiment 1. However, the continuous EEG was cut into epochs $1,000 \mathrm{msec}$ in duration. The epochs were time locked to the onset of the cues, starting $100 \mathrm{msec}$ before and ending $900 \mathrm{msec}$ after cue onset. The LPP was quantified as the mean amplitude in the latency range from 400-700 msec after stimulus onset at the parietal electrode, $\mathrm{P}_{\mathrm{z}}$.

\section{Results}

\section{Ratings of Emotional Valence and Arousal}

The results that were obtained from spider-fearful and snake-fearful individuals are displayed in Table 4. As in Experiment 1, the phobia-related pictures achieved more negative ratings of emotional valence and arousal than did the phobia-unrelated pictures of animals for both groups of participants. Apart from this phobia-specific response pattern, the two groups displayed comparable emotional responses to the pictures of all faces and to the shocks and coins. The pictures of human faces generally elicited medium ratings of emotional valence and medium to low ratings of emotional arousal. Coins/shocks were associated with positive or negative ratings of emotional valence, respectively, and with medium ratings of emotional arousal.

\section{Contingency Ratings}

Mean ratings of contingencies between cues and outcomes that were obtained from spider-fearful and snakefearful individuals are displayed in Table 5. The ratings of the contingencies between animal pictures and outcomes were analyzed using an ANOVA with the factors group (spider-fearful, snake-fearful), animal category (spider, snake), motivational context (aversive with shock

Table 4

Emotional Valence and Arousal Associated With All Stimuli in Experiment 2

\begin{tabular}{|c|c|c|c|c|c|c|c|c|}
\hline \multirow[b]{3}{*}{ Stimuli } & \multicolumn{4}{|c|}{ Valence } & \multicolumn{4}{|c|}{ Arousal } \\
\hline & \multicolumn{2}{|c|}{ Spider Fearful } & \multicolumn{2}{|c|}{ Snake Fearful } & \multicolumn{2}{|c|}{ Spider Fearful } & \multicolumn{2}{|c|}{ Snake Fearful } \\
\hline & $M$ & $S D$ & $M$ & $S D$ & $M$ & $S D$ & $M$ & $S D$ \\
\hline Spider 1 & 8.2 & 1.1 & 5.6 & 1.2 & 7.3 & 1.6 & 3.3 & 1.5 \\
\hline Spider 2 & 8.2 & 0.8 & 5.1 & 1.0 & 6.9 & 2.0 & 2.6 & 1.4 \\
\hline Snake 1 & 4.3 & 1.6 & 8.4 & 0.8 & 4.0 & 2.3 & 7.4 & 1.4 \\
\hline Snake 2 & 5.1 & 1.4 & 8.3 & 0.7 & 4.8 & 2.2 & 7.1 & 1.7 \\
\hline Face 1 & 4.0 & 1.5 & 4.7 & 1.2 & 2.5 & 1.8 & 1.5 & 0.9 \\
\hline Face 2 & 3.3 & 1.3 & 3.6 & 1.2 & 2.3 & 1.8 & 1.4 & 0.7 \\
\hline Face 3 & 6.2 & 1.6 & 5.8 & 1.2 & 4.1 & 1.9 & 3.6 & 2.2 \\
\hline Face 4 & 3.4 & 1.7 & 3.4 & 1.2 & 2.5 & 1.8 & 1.5 & 1.1 \\
\hline Face 5 & 4.6 & 1.5 & 4.6 & 1.2 & 2.9 & 1.9 & 1.9 & 1.5 \\
\hline Face 6 & 5.2 & 1.6 & 4.9 & 1.2 & 3.3 & 2.2 & 2.1 & 1.9 \\
\hline Face 7 & 4.5 & 1.7 & 4.6 & 1.2 & 2.8 & 2.1 & 1.5 & 1.3 \\
\hline Face 8 & 4.4 & 1.3 & 4.1 & 1.2 & 2.8 & 2.1 & 2.1 & 1.5 \\
\hline Coins & 1.9 & 1.4 & 2.4 & 0.7 & 4.6 & 1.9 & 4.2 & 2.6 \\
\hline Shock & 7.0 & 0.0 & 7.0 & 0.0 & 4.7 & 1.4 & 4.2 & 1.6 \\
\hline
\end{tabular}

Note-The highest $M$ of a group of participants is presented in boldface; the lowest $M$ of a group of participants is italicized. Valence and arousal assessments were obtained on rating scales ranging from 1 (pleasant) to 9 (unpleasant) and 1 (not arousing) to 9 (highly arousing), respectively. Faces 1-4 were female, and Faces 5-8 were male. outcome, appetitive with coins outcome), and block of trials (first, second, third). The ANOVA revealed a significant main effect of motivational context $[F(1,30)=$ $\left.13.1, M S_{\mathrm{e}}=119.0, \omega^{2}=0.28, p<.01\right]$, indicating that the ratings of the contingencies between animal pictures and outcomes were higher in the aversive than in the appetitive context. In addition, significant interaction effects emerged: motivational context $\times$ block $[F(1,30)=$ $\left.5.0, M S_{\mathrm{e}}=30.2, \omega^{2}=0.11, p<.05\right]$; group $\times$ animal $\left[F(1,30)=7.5, M S_{\mathrm{e}}=97.1, \omega^{2}=0.17, p<.01\right]$; and group $\times$ animal $\times$ motivational context $[F(1,30)=4.7$, $\left.M S_{\mathrm{e}}=59.8, \omega^{2}=0.10, p<.05\right]$. To parse the three-way interaction, two ANOVAs [group (spider-fearful, snakefearful) $\times$ animal (spider, snake) $\times$ block of trials (first, second, third)] were conducted separately for the aversive and appetitive motivational contexts. The group $\times$ animal interaction proved significant in the aversive motivational context $\left[F(1,30)=11.4, M S_{\mathrm{e}}=83.7, \omega^{2}=0.25, p<.01\right]$, yet it failed to reach significance in the appetitive motivational context $[F(1,30)<1]$. Inspection of Table 5 reveals that this pattern of results indicates the occurrence of a covariation bias in the aversive motivational context that was clearly absent in the appetitive motivational context. Contingency ratings between faces and outcomes were analyzed using an ANOVA with the factors group (spider fearful, snake fearful), accompanying animal category (spider, snake), motivational context (aversive with shock outcome, appetitive with coins outcome), and block of trials (first, second, third). Here, only the group $\times$ motivational context $\times$ block interaction proved significant $\left[F(1,30)=5.9, M S_{\mathrm{e}}=91.2, \omega^{2}=0.13, p<\right.$ $.05]$, whereas the group $\times$ animal $\times$ motivational context interaction $\left[F(1,30)=2.7, M S_{\mathrm{e}}=111.1, \omega^{2}=0.05, p=\right.$ .11] failed to reach statistical significance. However, when two ANOVAs [group (spider fearful, snake fearful) $\times$ animal category (spider, snake) $\times$ block of trials (first, second, third)] were conducted separately for the aversive and appetitive motivational contexts, the group $\times$ animal interaction once again proved significant in the aversive $\left[F(1,30)=6.6, M S_{\mathrm{e}}=85.6, \omega^{2}=0.15, p<.05\right]$ but not in the appetitive $[F(1,30)<1]$ motivational context. Inspection of Table 5 reveals that the two-way interaction in the aversive motivational context was due to reduced ratings of the contingencies between faces and shocks when the faces were accompanied by phobia-related rather than -unrelated pictures of animals - that is, a phobia-related cue competition effect.

\section{Event-Related Brain Potentials}

P1 and N1. Figure 5 depicts the ERPs that were obtained in response to phobia-related versus -unrelated pictures of animals across the scalp. P1 and N1 are again dominant in the waveforms at occipito-temporal electrodes. The ANOVA for the peak amplitude of the P1 at the occipital electrodes [phobia group (spider fearful, snake fearful) $\times$ animal category (spiders, snakes) $\times$ motivational context (aversive, appetitive) $\times$ electrode position $\left(\mathrm{O}_{1}, \mathrm{O}_{2}\right)$ ] revealed a significant main effect of 
Table 5 Contingency Ratings (\%) in Experiment 2

\begin{tabular}{|c|c|c|c|c|}
\hline \multirow[b]{2}{*}{ Stimuli } & \multicolumn{2}{|c|}{ Spider Fearful } & \multicolumn{2}{|c|}{$\underline{\text { Snake Fearful }}$} \\
\hline & $M$ & $S D$ & $M$ & $S D$ \\
\hline \multicolumn{5}{|c|}{ Aversive Context } \\
\hline \multicolumn{5}{|l|}{ Pictures of animals } \\
\hline Spiders & 59.0 & 8.1 & 55.1 & 5.3 \\
\hline Snakes & 54.0 & 5.8 & 61.0 & 12.3 \\
\hline \multicolumn{5}{|l|}{ Pictures of faces } \\
\hline Spiders accompanying (female) & 78.0 & 10.1 & 81.7 & 8.1 \\
\hline Snakes accompanying (male) & 83.1 & 7.8 & 78.4 & 9.7 \\
\hline \multicolumn{5}{|c|}{ Appetitive Context } \\
\hline \multicolumn{5}{|l|}{ Pictures of animals } \\
\hline Spiders & 54.5 & 6.3 & 52.2 & 5.8 \\
\hline Snakes & 51.2 & 5.1 & 51.4 & 8.6 \\
\hline \multicolumn{5}{|l|}{ Pictures of faces } \\
\hline Spiders accompanying (female) & 80.2 & 13.9 & 79.0 & 9.1 \\
\hline Snakes accompanying (male) & 81.4 & 8.6 & 80.4 & 10.7 \\
\hline
\end{tabular}

Note-Actual contingencies were $50 \%$ for pictures of animals and $80 \%$ for pictures of faces.

animal $\left[F(1,30)=10.8, M S_{\mathrm{e}}=5.3, \omega^{2}=0.24, p<.01\right]$ and two two-way interaction effects: animal $\times$ electrode $\left[F(1,30)=17.2, M S_{\mathrm{e}}=1.0, \omega^{2}=0.34, p<.01\right]$ and motivational context $\times$ electrode $\left[F(1,30)=6.6, M S_{\mathrm{e}}=\right.$ $\left.0.2, \omega^{2}=0.15, p<.05\right]$. Snake pictures led to more pronounced $\mathrm{P} 1$ peaks than did spider pictures, particularly at $\mathrm{O}_{1}$. The ANOVA for the peak amplitude of the N1 at the temporal electrodes [phobia group (spider fearful, snake fearful) $\times$ animal category (spiders, snakes) $\times$ motivational context (aversive, appetitive) $\times$ electrode position $\left.\left(\mathrm{T}_{5}, \mathrm{~T}_{6}\right)\right]$ revealed a significant animal main effect $\left[F(1,30)=15.6, M S_{\mathrm{e}}=13.6, \omega^{2}=0.31, p<.01\right]$, as well as an interaction of animal and electrode $[F(1,30)=$ $\left.5.5, M S_{\mathrm{e}}=9.0, \omega^{2}=0.12, p<.01\right]$; snake pictures led to more pronounced $\mathrm{N} 1$ peaks than did spider pictures, particularly at $\mathrm{T}_{5}$.

SP and SN. Figure 6 depicts the SP at the frontal electrodes, and Figure 7 depicts the $\mathrm{SN}$ at the occipital electrodes. Inspection of the difference waves in Figure 6 reveals that the SP is a frontally positive deflection $($ less than $+1 \mu \mathrm{V})$ of the ERP in response to phobiarelated rather than -unrelated animals that peaks at around $200 \mathrm{msec}$ after stimulus onset. Similarly, inspection of the difference waves in Figure 7 reveals that the SN is a negative deflection at the occipital electrodes (less than $-2 \mu \mathrm{V}$ ) of the ERP in response to phobia-related rather than -unrelated animals and that it peaks at around $200 \mathrm{msec}$ after stimulus onset. The ANOVA for the mean amplitude of the SP at the frontal electrodes [phobia group (spider fearful, snake fearful) $\times$ animal category (spiders, snakes) $\times$ motivational context (aversive, appetitive) $\times$ electrode position $\left(\mathrm{F}_{3}, \mathrm{~F}_{\mathrm{z}}, \mathrm{F}_{4}\right)$ ] revealed a significant animal main effect $\left[F(1,30)=6.3, M S_{\mathrm{e}}=4.6, \omega^{2}=0.14\right.$, $p<.05]$ and a significant group $\times$ animal interaction $\left[F(1,30)=8.1, M S_{\mathrm{e}}=4.6, \omega^{2}=0.18, p<.01\right]$. As in Experiment 1, the indicated modulation of the ERP by the phobia relatedness of animal pictures at the frontal electrodes in the latency range from 160-230 msec after stimulus onset (Figure 6) proved to be statistically reliable. In contrast, motivational context clearly did not influence the SP, because the three-way interaction group $\times$

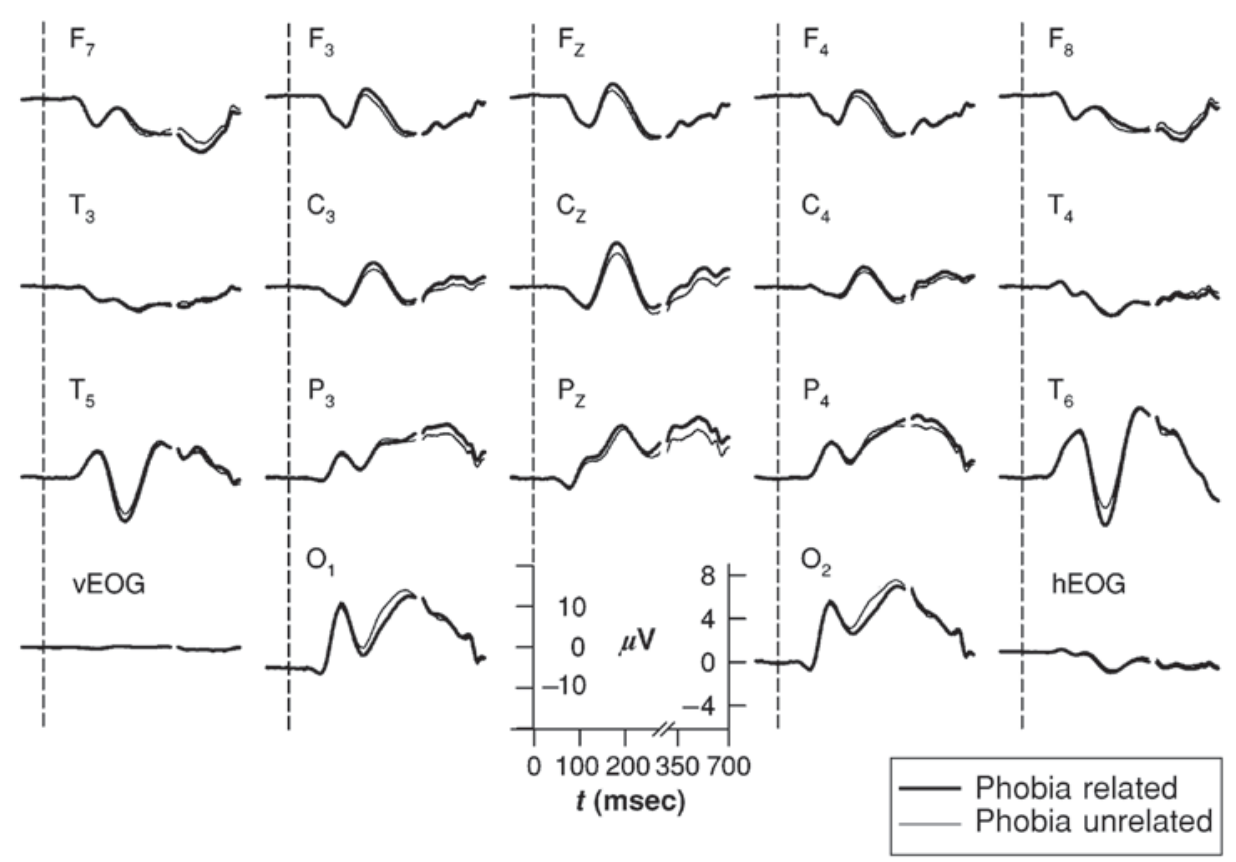

Figure 5. Grand average event-related potential (ERP) waveforms elicited by phobia-related and -unrelated pictures of animals in Experiment 2. Stimulus onset was at $t=0$. Scaling on the left corresponds to the electrooculogram (EOG); scaling on the right is for the ERP. vEOG, vertical EOG; hEOG, horizontal EOG. 

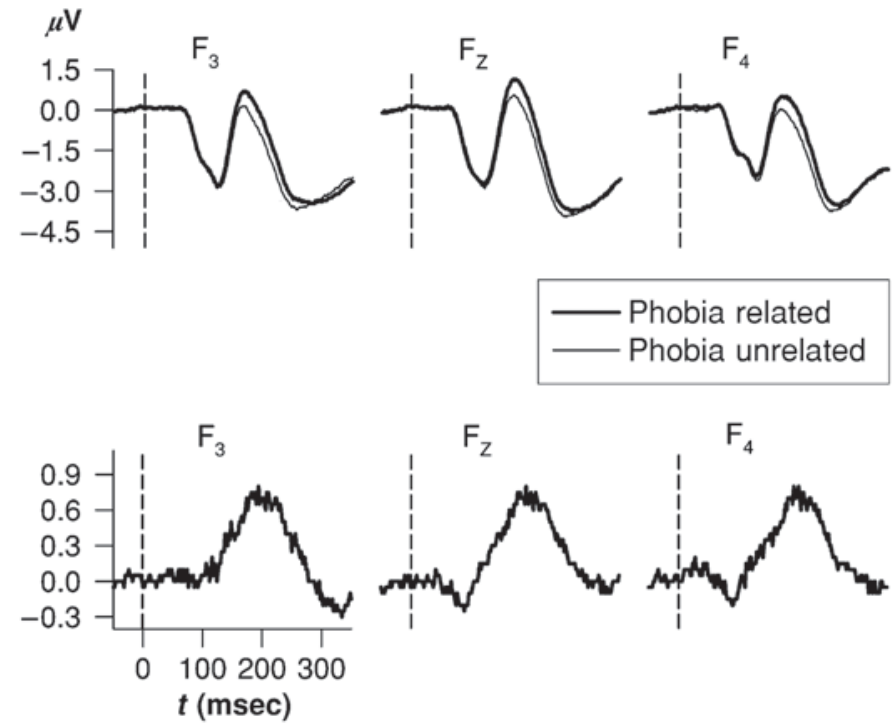

Figure 6. (Upper panel) Frontal grand average event-related potential (ERP) waveforms elicited by phobia-related and -unrelated pictures of animals in Experiment 2. (Lower panel) Difference waves obtained by subtracting the ERP for phobia-unrelated stimuli from that for phobiarelated stimuli. Stimulus onset was at $t=0$.

animal $\times$ motivational context was not significant $[F(1,30)<1]$. A similar pattern of results was obtained from the ANOVA for the mean amplitude of the $\mathrm{SN}$ at the occipital electrodes [phobia group (spider fearful, snake fearful) $\times$ animal category (spiders, snakes) $\times$ motivational context (aversive, appetitive) $\times$ electrode position $\left.\left(\mathrm{O}_{1}, \mathrm{O}_{2}\right)\right]$. The group $\times$ animal interaction $[F(1,30)=$ 9.1, $\left.M S_{\mathrm{e}}=6.9, \omega^{2}=0.2, p<.01\right]$ proved significant, but not the group $\times$ animal $\times$ motivational context interaction $[F(1,30)<1]$. Thus, modulation of the ERPs by the phobia relatedness of animal pictures at the occipital electrodes in the latency range from $175-275 \mathrm{msec}$ after stimulus onset (Figure 7) was statistically reliable and was uninfluenced by motivational context.

LPP. Finally, the mean amplitude of the LPP at parietal electrode $P_{z}$ (see Figure 5) was fed into a statistical analysis. The phobia group (spider fearful, snake fearful) $\times$ animal category (spiders, snakes) $\times$ motivational context (aversive, appetitive) ANOVA revealed a significant animal main effect $\left[F(1,30)=8.4, M S_{\mathrm{e}}=3.3, \omega^{2}=0.19, p<.01\right]$, as well
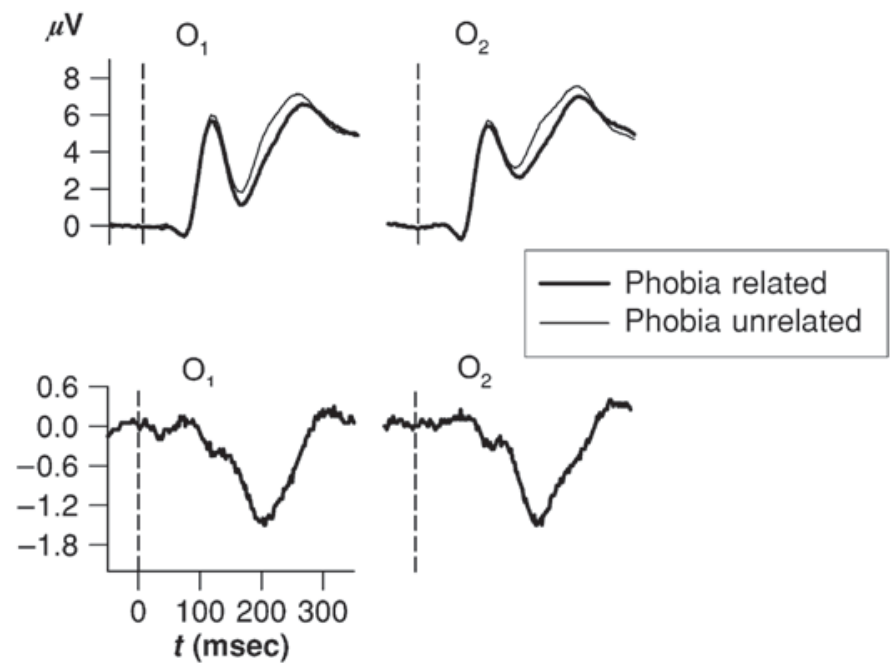

Figure 7. (Upper panel) Occipital grand average event-related potential (ERP) waveforms elicited by phobia-related and -unrelated pictures of animals in Experiment 2. (Lower panel) Difference waves obtained by subtracting the ERP for phobia-unrelated stimuli from that for phobiarelated stimuli. Stimulus onset was at $t=0$. 
as a significant group $\times$ animal interaction $[F(1,30)=12.2$, $\left.M S_{\mathrm{e}}=3.3, \omega^{2}=0.26, p<.01\right]$. Once again, the group $\times$ animal $\times$ motivational context interaction was not significant $[F(1,30)<1]$. Thus, in a replication of the results obtained in Experiment 1, the SP, SN, and LPP were all modulated by the phobia relatedness of the animal pictures, and none of these effects was modulated when the motivational context was manipulated in Experiment 2.

\section{GENERAL DISCUSSION}

Neither the SP, the SN, nor the LPP, all of which were influenced by the phobia relatedness of animal pictures in both experiments, was modulated by the motivationalaffective bias of the motivational context in Experiment 2. Taken together, the ERP results of both experiments provide strong evidence for replicable phobia-related attentional amplification of sensory-perceptual processing in the extrastriate visual cortex. The processing of threatening information, although clearly involving subcortical regions such as the amygdala, is not limited to those regions but rather involves a wide range of brain systems, including sensory-perceptual cortical areas. No evidence for additional cortico-cortical control of attentional amplification could be discerned in the present study, since no evidence could be obtained for an influence of motivational-affective state on amplified activity in the extrastriate cortex. This finding suggests that the modulation of sensory-perceptual processing occurs primarily as part of a bottom-up route. Given the anatomical knowledge about the central fear responses in animals and humans (Davis, 1992; Kalin et al., 2004; LeDoux, 2000), the amygdala is likely to be involved in phobia-related attentional amplification. Amygdaloid-extrastriate cortex pathways have been described (Amaral et al., 1992), and this connectivity may well be the neural substrate of phobia-related modulation of the SN. The reasons why phobia-related modulation of the SN, rather than of the SP or the LPP, is highlighted here have been described in the Discussion of Experiment 1 , so there is no need to reiterate them here.

These ERP findings provide an initial clue about the interconnections between emotional and attentional processing: Emotional and attentional SN effects represent the amplification of sensory-perceptual processing in identical, or at least similar, cortical areas. However, whereas attentional SN effects are typically induced by way of verbal instructions (i.e., by control from higher order centers of the brain), the evidence presented here suggests that emotional SN effects mainly occur as a corollary of bottom-up modulation.

The fast detection of yet unknown perceptual features of phobia-related information is among the psychological mechanisms of phobia-related attentional amplification. Those feature detectors (Öhman, 2000) are reminiscent of James's (1890) notion of a particular variant of attention - namely, "passive immediate sensorial attention" (p. 416) - in which the stimulus is a sense impression that may be "an instinctive stimulus, a perception which, by reason of its nature rather than its mere force, appeals to some of our normal congenital impulses and has a directly exciting quality" (p. 417).

The pattern of cognitive effects of phobia-related stimuli across the two experiments stood in contrast to the pattern of ERP effects. The covariation bias, the overassessment of the contingencies between phobia-related and aversive stimuli, occurred only in the purely aversive motivational-affective context of Experiment 2; it was absent in mixed (Experiment 1) and in purely appetitive (Experiment 2) motivational contexts. However, phobiarelated cue competition, the underassessment of the contingencies between neutral and aversive stimuli when pairings of phobia-related and aversive stimuli were presented simultaneously, occurred in mixed (Experiment 1) as well as in purely aversive (Experiment 2) motivational contexts. Thus, the patterns of occurrence of the two cognitive effects of phobia-related stimuli in animal-fearful individuals differed; moreover, they both differed from the pattern of occurrence of the ERP effects of phobiarelated stimuli.

The covariation bias occurs in MCPL in aversively biased motivational-affective contexts. Our earlier finding of a lack of covariation bias in MCPL when mixed motivational contexts were applied (Kopp et al., 2003) concurs well with this conclusion. Furthermore, the conclusion also agrees with results in the available literature on covariation bias in other paradigms in which the use of aversively biased motivational-affective contexts is the rule (Tomarken et al., 1995). Covariation bias was related to a dominant aversive state, and its occurrence may be conditional on the predominant retrieval of aversive episodes from associative emotional memory (Kopp, Schlimm, \& Hermann, 2005).

The pattern of occurrence of phobia-related cue competition differed from the pattern for phobia-related attentional amplification, since it occurred in the mixed as well as in the purely aversive, but not in the purely appetitive, motivational context. Thus, the mechanisms that lead to phobia-related cue competition differ from the ones that lead to attentional amplification. The dissociation between phobia-related attentional amplification and phobia-related cue competition in the purely appetitive motivational context may be explainable with the notion that phobia-related cue competition is discernible if and only if belonging (Hamm et al., 1989) pairings between phobia-related and aversive stimuli interfere with the accruing of associative strength between the neutral and aversive stimuli under consideration. According to this account, the elaboration in memory (e.g., rehearsing or reactivating) of belonging pairs of stimuli (phobia-related and aversive) disrupts the elaboration of nonbelonging pairs of stimuli (neutral and aversive). Importantly, the elaboration of belonging pairs of stimuli in memory may occur as a psychological corollary of amygdalar involvement in aversively motivated associative learning (see, e.g., Davis, 1992; Phelps \& Anderson, 1997; Poremba \& Gabriel, 1997, 1999; see also Kopp et al., 2005).

Although animal phobia possesses limited clinical relevance, this circumscribed mental disorder offers a valuable 
scientific model for investigating some of the neurocognitive mechanisms of exaggerated fear. Further research on this model disorder will help delineate the neural and psychological interconnections between emotional and attentional processing. The general implication of our findings is that the neural and psychological processes that are often assumed to fall into the separate categories of cognition (attention) and emotion (fear) are actually deeply intertwined. In addition, the present approach offers a route toward the neuropsychopharmacological assay of the neurocognitive effects of anxiolytic drugs.

\section{REFERENCES}

Amaral, D. G., Price, J. L., Pitkanen, A., \& Carmichael, S. T. (1992). Anatomical organization of the primate amygdaloid complex. In J. P Aggleton (Ed.), The amygdala: Neurobiological aspects of emotion, memory, and mental dysfunction (pp. 1-66). New York: Wiley-Liss.

BaAs, J. M. P., Kenemans, J. L., Böcker, K. B. E., \& Verbaten, M. N (2002). Threat-induced cortical processing and startle potentiation. NeuroReport, 13, 133-137.

BERG, P. (1986). The residual after correcting event-related potentials for blink artifacts. Psychophysiology, 23, 354-364.

Bradley, M. M., Greenwald, M. K., Petry, M. C., \& Lang, P. J. (1992). Remembering pictures: Pleasure and arousal in memory. Journal of Experimental Psychology: Learning, Memory, \& Cognition, 18, 379-390.

Carretié, L., Martin-Loeches, M., Hinojosa, J. A., \& Mercado, F. (2001). Emotion and attention interaction studied through eventrelated potentials. Journal of Cognitive Neuroscience, 13, 1109-1128.

Compton, R. J. (2003). The interface between emotion and attention: A review of evidence from psychology and neuroscience. Behavioral \& Cognitive Neuroscience Reviews, 2, 115-129.

Cuthbert, B. N., Schupp, H. T., Bradley, M. M., Birbaumer, N., \& LANG, P. J. (2000). Brain potentials in affective picture processing: Covariation with autonomic arousal and affective report. Biological Psychology, 52, 95-111.

Cuthbert, B. N., Schupp, H. T., Bradley, M. M., McManis, M., \& LANG, P. J. (1998). Probing affective pictures: Attended startle and tone probes. Psychophysiology, 35, 344-347.

DAVIDSON, R. J. (2003). Affective neuroscience and psychophysiology: Toward a synthesis. Psychophysiology, 40, 655-665.

DAVIS, M. (1992). The role of the amygdala in conditioned fear. In J. P. Aggleton (Ed.), The amygdala: Neurobiological aspects of emotion, memory, and mental dysfunction (pp. 255-306). New York: Wiley-Liss.

Dilger, S., Straube, T., Mentzel, H.-J., Fitzek, C., Reichenbach, J. R., Hecht, H., ET AL. (2003). Brain activation to phobia-related pictures in spider phobic humans: An event-related functional magnetic resonance imaging study. Neuroscience Letters, 348, 29-32.

Fredrikson, M., Wik, G., Annas, P., Ericson, K., \& Stone-Elander, S. (1995). Functional neuroanatomy of visually elicited simple phobic fear: Additional data and theoretical analysis. Psychophysiology, 32, 43-48.

Fredrikson, M., WiK, G., Greitz, T., Eriksson, L., Stone-Elander, S., ERICSON, K., \& Sedvall, G. (1993). Regional cerebral blood flow during experimental phobic fear. Psychophysiology, 30, 126-130.

FyER, A. J. (1998). Current approaches to etiology and pathophysiology of specific phobia. Biological Psychiatry, 44, 1295-1304.

Globisch, J., Hamm, A. O., Esteves, F., \& Öhman, A. (1999). Fear appears fast: Temporal course of startle reflex potentiation in animal fearful subjects. Psychophysiology, 36, 66-75.

Hagemann, D., Naumann, E., \& Thayer, J. F. (2001). The quest for the EEG reference revisited: A glance from brain asymmetry research. Psychophysiology, 38, 847-857.

Hamm, A. O., VaITL, D., \& LANG, P. J. (1989). Fear conditioning, meaning, and belongingness: A selective association analysis. Journal of Abnormal Psychology, 98, 395-406.

HARTER, M. R., \& Aine, C. J. (1984). Brain mechanisms of visual selective attention. In R. Parasuraman \& D. R. Davies (Eds.), Varieties of attention (pp. 293-321). New York: Academic Press.
Hautzinger, M., \& Bailer, M. (1993). Allgemeine Depressions Skala (ADS) [CES depression scale]. Weinheim: Beltz.

Hillyard, S. A. (1993). Electrical and magnetic brain recordings: Contributions to cognitive neuroscience. Current Opinion in Neurobiology, 3, 217-224.

Hillyard, S. A., Teder-Sälejärvi, W. A., \& Münte, T. F. (1998). Temporal dynamics of early perceptual processing. Current Opinion in Neurobiology, 8, 202-210.

JAMES, W. (1890). The principles of psychology (2 vols.). New York: Holt.

Johanson, A., Gustafson, L., Passant, U., Risberg, J., Smith, G. WARKentin, S., \& TuCKER, D. (1998). Brain function in spider phobia. Psychiatry Research, 84, 101-111.

Kalin, N. H., Shelton, S. E., \& Davidson, R. J. (2004). The role of the central nucleus of the amygdala in mediating fear and anxiety in the primate. Journal of Neuroscience, 24, 5506-5515.

Kayser, J., Tenke, C., Nordby, H., Hammerborg, D., Hugdahl, K., \& ERDMANN, G. (1997). Event-related potential (ERP) asymmetries to emotional stimuli in a visual half-field paradigm. Psychophysiology, 34, 414-426.

Keil, A., Bradley, M. M., Hauk, O., Rockstroh, B., Elbert, T., \& LANG, P. J. (2002). Large-scale neural correlates of affective picture processing. Psychophysiology, 39, 641-649.

Keil, A., Gruber, T., Müller, M. M., Moratti, S., Stolarova, M., Bradley, M. M., \& LANG, P. J. (2003). Early modulation of visual perception by emotional arousal: Evidence from steady-state visual evoked brain potentials. Cognitive, Affective, \& Behavioral Neuroscience, 3, 195-206.

Keil, A., Müller, M. M., Gruber, T., Wienbruch, C., Stolarova, M. \& ElBERT, T. (2001). Effects of emotional arousal in the cerebral hemispheres: A study of oscillatory brain activity and event-related potentials. Clinical Neurophysiology, 112, 2057-2068.

Kenemans, J. L., KoK, A., \& Smulders, F. T. (1993). Event-related potentials to conjunctions of spatial frequency and orientation as a function of stimulus parameters and response requirements. Electroencephalography \& Clinical Neurophysiology, 88, 51-63.

Klorman, R., Weerts, T. C., Hastings, J. E., Melamed, B. G., \& LANG, P. J. (1974). Psychometric description of some specific-fear questionnaires. Behavior Therapy, 5, 401-409.

Kopp, B., Altmann, R., \& Hermann, C. (2003). Multiple-cue probabilistic learning in spider-fearful and in panic-prone individuals. Journal of Behavior Therapy \& Experimental Psychiatry, 34, 101-115.

Kopp, B., Schlimm, M., \& Hermann, C. (2005). Memory-emotional interactions as revealed by fear generalization in animal-fearful individuals. Journal of Behavior Therapy \& Experimental Psychiatry, 36, 145-166.

KopP, B., \& WolfF, M. (2000). Brain mechanisms of selective learning: Event-related potentials provide evidence for error-driven learning in humans. Biological Psychology, 51, 223-246.

Kruschke, J. K., \& Johansen, M. K. (1999). A model of probabilistic category learning. Journal of Experimental Psychology: Learning, Memory, \& Cognition, 25, 1083-1119.

Lang, P. J., Bradley, M. M., \& Cuthbert, B. N. (1998). Emotion, motivation, and anxiety: Brain mechanisms and psychophysiology. Biological Psychiatry, 44, 1248-1263.

LANG, P. J., Davis, M., \& ÖHman, A. (2000). Fear and anxiety: Animal models and human cognitive psychophysiology. Journal of Affective Disorders, 61, 137-159.

LeDoux, J. E. (2000). Emotion circuits in the brain. Annual Review of Neuroscience, 23, 155-184.

Martínez, A., Di Russo, F., Anllo-Vento, L., \& Hillyard, S. A. (2001). Electrophysiological analysis of cortical mechanisms of selective attention to high and low spatial frequencies. Clinical Neurophysiology, 112, 1980-1998.

Mazurski, E. J., \& Bond, N. W. (1993). A new series of slides depicting facial expression of affect: A comparison with the pictures of facial affect series. Australian Journal of Psychology, 45, 41-47.

Miller, E. K., \& CoHen, J. D. (2001). An integrative theory of prefrontal cortex function. Annual Review of Neuroscience, 24, 167-202.

ÖHman, A. (2000). Fear and anxiety: Evolutionary, cognitive, and clinical perspectives. In M. Lewis \& J. M. Haviland-Jones (Eds.), Handbook of emotions (2nd ed., pp. 573-593). New York: Guilford.

Öhman, A., Flykt, A., \& Esteves, F. (2001). Emotion drives attention: 
Detecting the snake in the grass. Journal of Experimental Psychology: General, 130, 466-478.

Öhman, A., \& MineKa, S. (2001). Fears, phobias, and preparedness: Toward an evolved module of fear and fear learning. Psychological Review, 108, 483-522.

Phelps, E. A., \& Anderson, A. K. (1997). Emotional memory: What does the amygdala do? Current Biology, 7, R311-R314.

Picton, T. W., Bentin, S., Berg, P., Donchin, E., Hillyard, S. A., JOHNSON, R., JR., ET AL. (2000). Guidelines for using human eventrelated potentials to study cognition: Recording standards and publication criteria. Psychophysiology, 37, 127-152.

Poremba, A., \& Gabriel, M. (1997). Amygdalar lesions block discriminative avoidance learning and cingulothalamic training-induced neuronal plasticity in rabbits. Journal of Neuroscience, 17, 5237-5244.

Poremba, A., \& Gabriel, M. (1999). Amygdala neurons mediate acquisition but not maintenance of instrumental avoidance behavior in rabbits. Journal of Neuroscience, 19, 9635-9641.

RESCORLA, R. A. (1988). Pavlovian conditioning: It's not what you think it is. American Psychologist, 43, 151-160.

Schendan, H. E., Ganis, G., \& Kutas, M. (1998). Neurophysiological evidence for visual perceptual categorization of words and faces within $150 \mathrm{~ms}$. Psychophysiology, 35, 240-251.
Schupp, H. T., Cuthbert, B. N., Bradley, M. M., Cacioppo, J. T., ITo, T., \& Lang, P. J. (2000). Affective picture processing: The late positive potential is modulated by motivational relevance. Psychophysiology, 37, 257-261.

Schupp, H. T., Junghofer, M., Weike, A. I., \& Hamm, A. O. (2003). Emotional facilitation of sensory processing in the visual cortex. Psychological Science, 14, 7-13.

Schupp, H. T., Junghofer, M., Weike, A. I., \& Hamm, A. O. (2004). The selective processing of briefly presented affective pictures: An ERP analysis. Psychophysiology, 41, 441-449.

Tomarken, A. J., Mineka, S., \& CoOK, M. (1989). Fear-relevant selective associations and covariation bias. Journal of Abnormal Psychology, 98, 381-394.

Tomarken, A. J., Sutton, S. K., \& Mineka, S. (1995). Fear-relevant illusory correlations: What types of associations promote judgmental bias? Journal of Abnormal Psychology, 104, 312-326.

WitTchen, H. U., Zaudig, M., \& Fydrich, T. (1997). Strukturiertes klinisches Interview für DSM-IV [Structured clinical interview for the DSM-IV]. Göttingen: Hogrefe.

(Manuscript received October 7, 2004; revision accepted for publication August 16, 2005.) 